\title{
ADRENAL LIPIDS IN PREGNANCY
}

\author{
D. P. SHARMA* AND T. A. VENKITASUBRAMANIAN
}

Vallabhbhai Patel Chest Institute, Delhi University, Delhi-7, India

(Received 30th May 1973)

Human adrenals have been reported to contain 40 to $50 \mathrm{mg}$ total cholesterol and $20 \mathrm{mg}$ phospholipids per $\mathrm{g}$ of tissue (Shohl, 1939). The adrenals of male Wistar rats have been found to contain $39.0 \mathrm{mg}$ phospholipids, $3.0 \mathrm{mg}$ free cholesterol, $50.4 \mathrm{mg}$ cholesterol ester, $2.2 \mathrm{mg}$ fatty acids and $18.0 \mathrm{mg}$ triglycerides per $\mathrm{g}$ tissue (Angelico, Cavina, D'Antona \& Giocoli, 1965). Observations on male guinea-pigs have revealed $230.3 \mathrm{mg}$ total lipids, $30.0 \mathrm{mg}$ phospholipids, $51.0 \mathrm{mg}$ esterified cholesterol and $10.97 \mathrm{mg}$ free cholesterol per $\mathrm{g}$ adrenal tissue (Misra, Misra \& Venkitasubramanian, 1965).

No information is available on the pattern of lipid changes in adrenals of guinea-pigs or other species during pregnancy. Details on phospholipid fractions and on incorporation studies of $\left[1-{ }^{14} \mathrm{C}\right]$ acetate are also lacking. The present investigation was undertaken to elicit the relevant information.

Female guinea-pigs of 5 to 6 months of age and in the $600-$ to $1000-\mathrm{g}$ body wt range were selected at random. The experimental group was mated and maintained to mid-pregnancy when they were killed. A non-pregnant group was studied simultaneously as controls. Intraperitoneal injection of $\left[1-{ }^{14} \mathrm{C}\right]-$ acetate (sp.act. $3.2 \mathrm{mCi} / \mathrm{mmol}$ ) was given to both groups at the rate of 10 $\mu \mathrm{Ci} / 100 \mathrm{~g}$ body weight $2 \mathrm{hr}$ before autopsy, when the adrenals were removed and weighed to a precision of $0.01 \mathrm{mg}$. The gland was homogenized in chloroform: methanol $(2: 1, \mathrm{v} / \mathrm{v})$, and the homogenate was centrifuged. The process was repeated three times, and the supernatants were pooled and dried at 40 to $45^{\circ} \mathrm{C}$ in vacuo. Proteolipids were split and non-lipid contaminants were eliminated (Folch, Lees \& Sloane-Stanley, 1957). The total lipid extract was fractionated by thin-layer chromatography for neutral lipids, using an $n$-hexane:diethylether-glacial acetic acid (60:40:1, by vol.) solvent system (Mangold, 1965). The plates $(20 \times 20 \mathrm{~cm})$ were developed up to a height of $7 \mathrm{~cm}$ in the solvent system, air-dried and subsequently run to $15 \mathrm{~cm}$ in a modified system comprising the same solvents in the ratio of $90: 10: 1$, respectively. A line was drawn just below the diglyceride spot, and the plates were again run up to this line in a third solvent system comprising the same solvent mixture in the respective proportions of $30: 70: 1$, which made the monoglycerides move up from the base line. Another aliquot of total lipid extract was fractionated for phospholipids by thin-layer chromatography, using the solvent system of Abramson \& Blecher (1964), consisting of chloroform:methanol: $7 \mathrm{~N}$-ammonia (115:45:7.5, by vol.).

\footnotetext{
* Present address: Faculty of Agriculture, University of Dar es Salaam, c/o Post Box 643, Morogoro, Tanzania.
} 


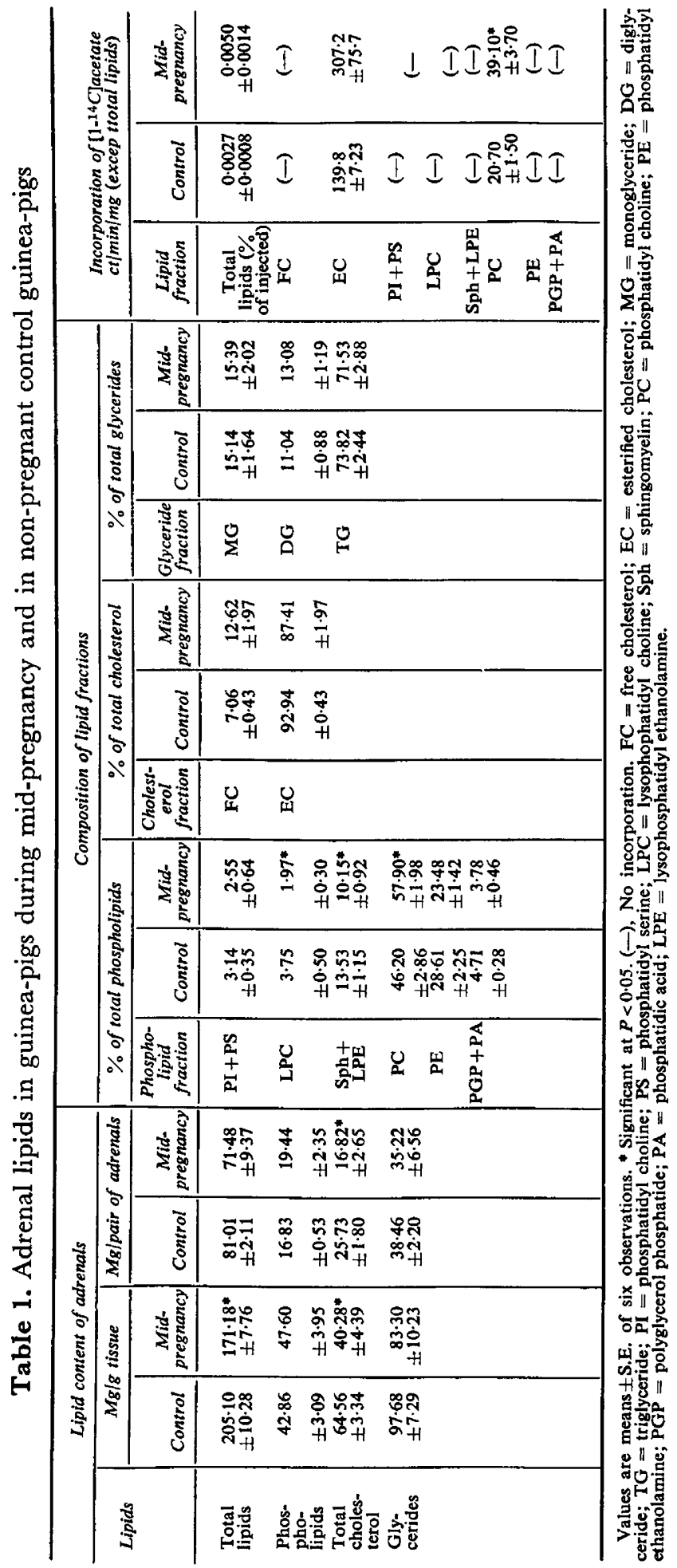


The spots were outlined in iodine vapour. Neutral lipid spots were eluted in chloroform. The phospholipid spots were eluted in the solvent mixture described by Abramson \& Blecher (1964) consisting of chloroform:methanol: formic acid:water (97:97:4:2). Radioactivity was estimated under a windowless gas-flow Geiger Muller counter (Tracer Lab.). Cholesterol was estimated by the method of Hanel \& Dam (1955), and glycerides by method of Van Handel \& Zilversmit (1957). The phosphorus content of the phospholipid fractions was estimated by the method of Bartlett (1959) as modified by Marinetti (1962), and phospholipid levels were calculated (i.e. $\mathrm{P} \times 25$ ).

The phospholipid contribution to the total lipid composition during pregnancy increased insignificantly, total cholesterol decreased significantly by $7.8 \%$ and the level of glycerides remained the same as in the non-pregnant controls (Table 1). A significant decrease occurred in total lipids and total cholesterol of the adrenals during pregnancy. The phospholipid:cholesterol ratio was elevated significantly (controls, $0 \cdot 66 \pm 0.05$; mid-pregnancy, $1 \cdot 18 \pm$ $0 \cdot 15 ; P<0.05)$ because of a diminution in the total cholesterol value, indicating an increased biological activity in the adrenals during pregnancy (Bloor, Okey \& Corner, 1930). Phosphatidyl choline showed a significant increase at the expense of other phospholipids during pregnancy. The ratio of free cholesterol: cholesterol ester was $1: 13$ in the control animals, and 1:7 in the pregnant animals suggesting an enhanced utilization of free cholesterol for steroidogenesis in the adrenals during pregnancy (Steinbeck \& Theile, 1962; Daessler, 1965). Studies on $\left[1-{ }^{14} \mathrm{C}\right]$ acetate incorporation indicated increased synthesis of total lipids, esterified cholesterol and phosphatidyl choline during pregnancy.

An interesting result of the incorporation studies was the significant reduction in adrenal cholesterol irrespective of its high rate of synthesis during pregnancy. This suggested that cholesterol was either excessively utilized by adrenals during pregnancy or was made available to other organs for their physiological needs.

\section{REFERENGES}

Abramson, D. \& Blecher, M. (1964) Quantitative two dimensional thin layer chromatography of naturally occurring phospholipids. F. Lipid Res. 5, 628.

Angelico, R., Gavina, G., D'Antona, A. \& Giocoli, G. (1965) Fractionation and determination of the lipid and steroid constituents of adrenal glands of rats by TLC. 7. Chromat. 18, 57.

Bartlett, G. R. (1959) Phosphorus assay in column chromatography. F. biol. Chem. 234, 466.

BlOOR, R., OKEY, R. \& CoRNER, G. W. (1930) The relation of lipids to physiological activity. I. The changes in lipid content of corpus luteum of sow. F. biol. Chem. 86, 291.

DessleR, C. G. (1965) The value of corticosteroid analyses in normal and pathological pregnancy. Abh. dt. Akad. Wiss. Berl. Kl. Med. 1, 153.

Folch, J., Lees, M. \& Sloane-Stanley, G. H. (1957) A simplified method for isolation and purification of total lipids from animal tissues. F. biol. Chem. 226, 497.

HANEL, H. K. \& DAM, H. (1955) Determination of small amounts of cholesterol by Tschugaeff reaction with a note on determination of lanosterol. Acta chem. scand. 9, 677.

Mangold, H. K. (1965) Aliphatic lipids. In: Thin Layer Chromatography. Ed. E. Stahl. Academic Press, New York.

MarinetTI, G. V. (1962) Chromatographic separation, identification and analysis of phosphatides. 7. Lipid Res. 3, 1.

Misra, R., Misra, U. K. \& Venkitasubramanian, T. A. (1965) Effect of dihydrostreptomycin on tissue lipids of guinea pigs. Nature, Lond. 207, 869. 
Sнонц, A. T. (1939) Mineral metabolism. Cited in: Biochemist's Handbook (1961), pp. 734-735. Ed. C. Long. Spon, London.

Steinbeck, A. W. \& Thene, H. (1962) Urinary steroids during pregnancy. Acta endocr., Copenh. 40, 123.

VAN HANDEL, E. \& Zilversmit, D. B. (1957) Micromethod for direct determination of triglycerides. 7. Lab. clin. Med. 50, 152. 